Int. J. Dev. Biol. 52: 677-682 (2008)

doi: $10.1387 / \mathrm{ijdb} .072528 \mathrm{ek}$

\title{
Sperm penetration through cumulus mass and zona pellucida
}

\author{
EKYUNE KIM, MISUZU YAMASHITA, MASANORI KIMURA, ARATA HONDA, SHIN-ICHI KASHIWABARA \\ and TADASHI BABA*
}

Graduate School of Life and Environmental Sciences, University of Tsukuba, Tsukuba Science City, Ibaraki, Japan

\begin{abstract}
Mammalian fertilization requires sperm to penetrate the cumulus mass and egg zona pellucida prior to fusion with the egg. Although sperm penetration through these physical barriers is essential, the molecular mechanism has not yet been completely elucidated. In addition to sperm motility, hyaluronan-hydrolyzing and proteolytic enzymes of sperm have been suggested to participate in the penetration events. Here we focus on the functional roles of hyaluronidase and protease in sperm passage through the cumulus mass and zona pellucida.
\end{abstract}

KEY WORDS: egg, zona pellucida, acrosome reaction, penetration, hyaluronidase, proteolysis

\section{Introduction}

Mammalian fertilization involves a precisely ordered set of molecular and cellular events, including sperm penetration through the cumulus mass, sperm adhesion and binding to the zona pellucida (ZP), an extracellular glycoprotein coat surrounding the egg, acrosome exocytosis, sperm penetration through the ZP, and fusion between sperm and egg (Yanagimachi, 1994; Snell and White, 1996; Wassarman, 1999; Florman and Ducibella, 2006). Capacitation of sperm possessing the intact acrosome is required for sperm entry into the cumulus mass (Austin, 1960, Yanagimachi, 1994). Sperm penetration of the cumulus mass is important for fertilization, because the fertilization rate is greatly reduced by removal of the cumulus in vitro (Yanagimachi, 1994). As shown in Fig. 1, a large number of experimental results reported so far raise the possibility that the cumulus may function in stimulating the sperm motility and in promoting the acrosome reaction, or may control the sperm access to the egg ZP immobilized by the fibrous network of the cumulus matrix (Yanagimachi, 1994; Florman and Ducibella, 2006). However, the role of the cumulus matrix still remains uncertain. Since cumulus cells are embedded in the extracellular matrix abundant in hyaluronan (hyaluronic acid), sperm hyaluronidase identified approximately 60 years ago has long been believed to catalyze hyaluronan degradation to enable acrosome-intact sperm to penetrate the cumulus matrix and then reach the ZP (Yanagimachi, 1994; Florman and Ducibella, 2006). Although sperm hyaluronidase has not been well characterized, the functional roles of several hyaluronidase isoforms are becoming clear in the mouse in recent years.
Binding of acrosome-intact sperm to the egg ZP induces sperm to undergo fusion between the plasma and outer acrosomal membranes at the anterior region of sperm head, acrosome reaction. As a consequence of the exocytotic event, the acrosomal components are released and interact with the ZP. In general, both mechanical and enzymatic mechanisms have been postulated to explain sperm entry into and penetration through the ZP (Yanagimachi, 1994). Only sperm motility is required for sperm penetration through the ZP in the former mechanism, whereas in the latter, the acrosomal enzymes are important and sperm motility is of second importance. Although acrosomal and membranous trypsin-like serine proteases may play an important role(s) in sperm passage through the ZP (Stambaugh et al., 1969; Miyamoto and Chang, 1973; Frazer, 1982; Yanagimachi, 1994), the true mechanism is still'unclear. Nevertheless, the physiological significance of the acrosome reaction and subsequent penetration of sperm through the ZP is that the fertilizing sperm acquires the ability to fuse with egg plasma membrane, because the fusion event is achieved only by acrosome-reacted sperm (Yanagimachi, 1994; Florman and Ducibella, 2006).

Despite the importance of sperm penetration through the cumulus cell layer and egg coat in mammalian fertilization, the molecular mechanism is still controversial. Indeed, the general concept, which has been believed for a long time, is overthrown by the experimental results obtained by using gene-knockout

Abbreviations used in this paper: GPI, glycosylphosphatidylinositol; ZP, zona pellucida.

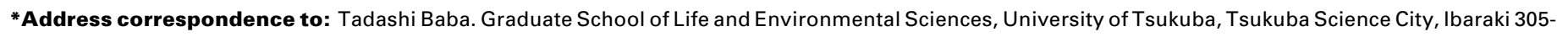
8572, Japan. Tel: +81-29-853-7196- Fax: +81-29-853-7196. Web: http://www.agbi.tsukuba.ac.jp/ tblab/ e-mail: acroman@sakura.cc.tsukuba.ac.jp

This paper is dedicated to the late Dr. David L. Garbers.

Published online: 4 July 2008 


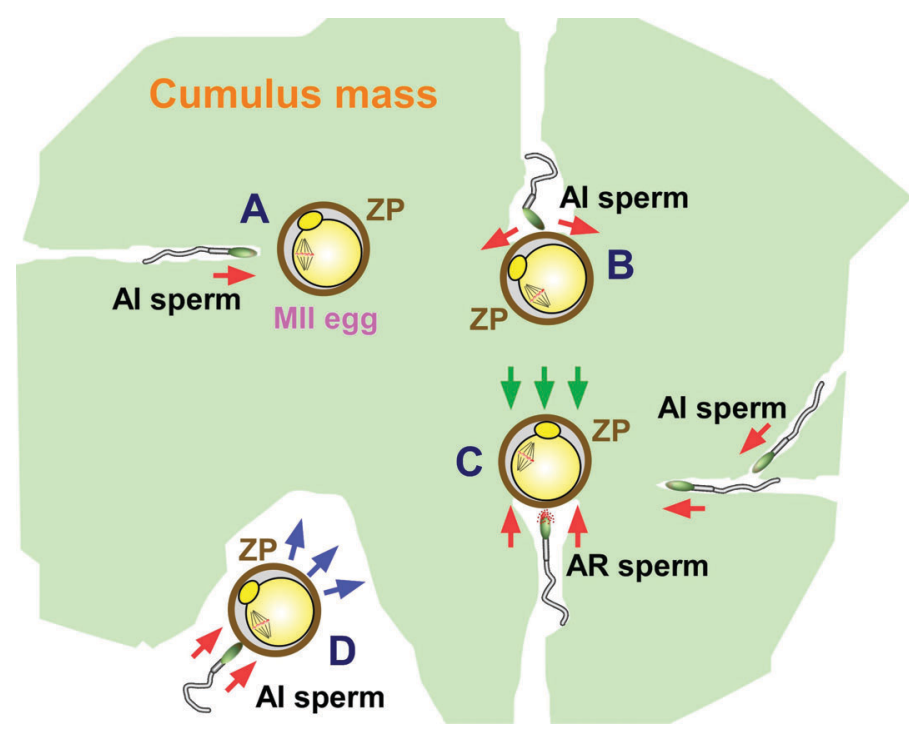

Fig. 1. Schematic model of sperm penetration through the cumulus mass. Capacitated, acrosome-intact (Al) sperm penetrate the cumulus mass to reach the zona pellucida (ZP) of metaphase II (MII)-arrested egg (A). Sperm hyaluronidase(s) may play an important role in sperm penetration through the cumulus and/or in local hyaluronan hydrolysis near or on the ZP surface to enable the proximal region of sperm tail to move freely (B). The cumulus may assist acrosome-reacting or acrosome-reacted $(A R)$ sperm in penetrating the $Z P$, because the egg movement is greatly blocked by the cumulus (C). When the cumulus is absent, the eggs migrate due to the force of sperm motility, thus resulting in the block of sperm penetration into the $Z P$ (D).

mice. Here we review our current knowledge of the mechanism of sperm penetration through the cumulus mass and egg ZP mainly in the mouse.

\section{Sperm penetration through the cumulus mass}

Hyaluronidase responsible for degradation of hyaluronan is distributed widely in mammals, insects, leeches, and bacteria (Kreil, 1995; Frost et al., 1996). There are at least two isoforms of hyaluronidase in mouse epididymal sperm. A glycosylphosphatidylinositol (GPI)-anchored membranous protein, $\mathrm{Ph}-20$, which was originally identified as a binding protein to the ZP in guinea pig sperm (Primakoff et al., 1985), is structurally similar to bee venom hyaluronidase. Indeed, $\mathrm{Ph}-20$ exhibits the hyaluronidase activity (Phelps et al., 1988; Gmachl and Kreil, 1993; Gmachl etal., 1993; Thaler and Cardullo, 1995; Cherr etal., 2001). $\mathrm{Ph}-20$ has long been thought to be the sole hyaluronidase involved in the sperm penetration through the cumulus mass, because other sperm hyaluronidase(s) were not characterized well. In 2002, mice carrying a targeted, disruptive mutation in Ph20 were produced by homologous recombination in embryonic stem cells (Baba et al., 2002). When total hyaluronidase activity of $n$-octyl- $\beta$-D-glucopyranoside protein extracts from acrosomeintact sperm is measured, the $\mathrm{Ph}$-20-deficient sperm extracts still contain approximately $40 \%$ of the enzyme activity in the wild-type sperm extracts. SDS-PAGE zymography in the presence of hyaluronan reveals that wild-type and $\mathrm{Ph}$-20-deficient mouse sperm both contain another hyaluronan-hydrolyzing protein, Hyal5, with a molecular size of $55 \mathrm{kDa}$. Since an enzymatically active $52-$ $\mathrm{kDa}$ protein is completely absent only in $\mathrm{Ph}-20$-deficient sperm, mouse epididymal sperm contain at least two isoforms of hyaluronidase, 52-kDa Ph-20 and 55-kDa Hyal5 (Baba et al., 2002; Kim et al., 2005).

The DNA-derived amino acid sequences indicate that mouse $\mathrm{Ph}-20$ and $\mathrm{Hyal} 5$ are initially synthesized as a single-chain polypeptide of 512 and 526 amino acids with calculated molecular masses of 58,520 and $60,807 \mathrm{Da}$, respectively (Kim et al., 2005). On the basis of the sequence similarity to guinea pig $\mathrm{PH}-20$, the 36 residue sequences of mouse $\mathrm{Ph}-20$ and $\mathrm{Hyal} 5$ at the $\mathrm{N}$-terminus are predicted to function as the signal sequence for a nascent protein destined for initial transfer to the endoplasmic reticulum (Fig. 2A). The C-terminal 30- and 26-residue sequences of Ph-20 and Hyal5, respectively, may act as a signal for the GPI attachment, because these two proteins are both GPI-anchored on the sperm membrane. The catalytic (hyaluronidase) domain of Hyal5, which is assigned to the 306-residue sequence at positions 37342 , shares a noticeable degree of sequence identity $(65 \%)$ with the corresponding region of $\mathrm{Ph}-20$. The locations of 12 Cys residues in Hyal5 are completely conserved with those in $\mathrm{Ph}-20$. Moreover, the entire sequences of $\mathrm{Ph}-20$ and Hyal5 are relatively divergent to those of other mouse hyaluronidases, Hyal1, Hyal2, Hyal4, and Hyalp1 (less than $40 \%$ identity). Noteworthy is that Hyal5 is a single-chain molecule structurally distinguishable from $\mathrm{Ph}-20$ consisting of two chains covalently linked by one of two preexisting disulfide bridges (Hunnicutt et al., 1996a and 1996b; Myles and Primakoff, 1997; Markovi-Housley et al., 2000; Kim et al., 2005). Indeed, the endoproteolytic cleavage-site sequences in guinea pig and mouse Ph-20, $\mathrm{Arg}^{346}-\mathrm{Ser}^{347}$ and $\mathrm{Arg}^{347}-\mathrm{Ala}^{348}$ are replaced by $\mathrm{Thr}^{347}-\mathrm{Met}^{348}$ in mouse Hyal5, respectively (Kim et al., 2005).

In the human and mouse, at least six hyaluronidase-like genes (seven genes for mouse) are clustered as two tightly linked triplets on two chromosomes (Csóka et al., 1999 and 2001; Kim et al., 2005): HYAL 1, HYAL2, and HYAL3on human chromosome 3p21 (Hyal1, Hyal2, and Hyal3 on mouse chromosome 9F1-F2), and HYAL4, PH-20/SPAM1, and HYALP1 on human chromosome 7q31 (Hyal4, Ph-20, Hyalp1, and Hyal5 on mouse chromosome 6A2). Both Ph-20and Hyal5 are a single-copy gene on the mouse genome, and contain four exons interrupted by three introns, and the translation initiator codon, ATG, is encoded within the second exons of Ph-20and Hyal5. A computer-aided search on the NCBI Genomic Biology database (http://www.ncbi.nlm.nih.gov/Genomes/) reveals that $H y a l 5$ is localized 57 kbps away from $P h-20$ on mouse chromosome 6A2 (Fig. 2B). Importantly, the genomic region carrying $H y a / 5$ is inserted onto the mouse, rat, and possibly hamster chromosomes (Kim et al., 2005). No Hyal5orthologous gene is present at least in the corresponding region of the human, pig, cow, and chimpanzee chromosomes. Mouse Hyal1, Hyal2, and $H y a / 3$ are ubiquitously expressed in all tissues, whereas expression of Hyalp1 and Hyal/5 is exclusive in the testis. Ph-20 and Hyal4 are expressed specifically in the testis and epididymis (Zhang and Martin-DeLeon, 2001; Kim et al., 2005), and in the placenta and skeletal muscle (Csóka et al., 1999), respectively. $P h-20$ and Hyal5mRNAs are first transcribed in the testis of 20day-old mice, and the mRNA levels progressively increase during testicular development. Moreover, hyaluronan zymography indicates that mouse epididymal sperm may contain only Ph-20 and 
Hyal5 (Kim et al., 2005). It should be noted that a research group has reported that Hyalp1, in addition to $\mathrm{Ph}-20$ and Hyal5, is enzymatically functional in sperm penetration of the cumulus in the mouse (Zhang et al., 2005; Miller et al., 2007), although other workers (Reitinger et al., 2007) provide evidence that recombinant Hyalp1 is incapable of hydrolyzing hyaluronan.

Although Ph-20 and Hyal5 are both GPI-anchored on the plasma or acrosomal membranes of mouse epididymal sperm, these two hyaluronidases differ from each other in the subcellular localization (Baba et al., 2002; Kim et al., 2005). Ph-20 is all present on the plasma membrane of acrosome-intact sperm, and the localization appears unchanged after the acrosome reaction. On the other hand, Hyal5 is localized both on the plasma (approximately $60 \%$ of total) and acrosomal membranes ( $40 \%)$. Most or all Hyal5 is released from the sperm membranes during the acrosome reaction. Thus, Hyal5 may function in sperm penetration through the cumulus mass, and in the local hyaluronan hydrolysis near or on the surface of the egg ZP to enable the proximal region of sperm tail to move freely (Kim et al., 2005). It is also suggested that $\mathrm{Ph}-20$ may compensate in part for the functional roles of Hyal5. In guinea pig and cynomolgus monkey, $\mathrm{PH}-20$ is distributed uniformly on the plasma membrane of sperm head, including the acrosome and equatorial segment (Phelps et al., 1990; Overstreet et al., 1995). Following the acrosome reaction $\mathrm{PH}-20$ is present on the inner acrosomal membrane and on the plasma membrane overlying the equatorial segment, indicating that $\mathrm{PH}-20$ may migrate from the plasma membrane of the posterior sperm head to the inner acrosomal membrane after acrosomal exocytosis. A soluble form of monkey $\mathrm{PH}-20$ is also released during the acrosome reaction (Cherr et al., 1996). It is thus conceivable that the localization of mouse $\mathrm{Ph}-20$ and Hyal5 is essentially similar to that of guinea pig and monkey $\mathrm{PH}-20$ on the acrosome-intact and acrosome-reacted sperm, although we need to ascertain the $\mathrm{PH}-20$ migration during the acrosome reaction.

$\mathrm{PH}-20$ from mouse and other animal origins has been reported to exhibit dual functions: the hualuronan-hydrolyzing and ZPbinding activities (Hunnicutt et al., 1996a and 1996b; Myles and Primakoff, 1997; Cherr et al., 2001). Particularly, PH-20 on the plasma membrane of acrosome-intact sperm and on the inner acrosomal membrane of acrosome-reacted sperm is thought to exhibit the hyaluronidase activity required for sperm penetration through the cumulus mass, and to participate in sperm-ZP binding known as "secondary sperm-ZP binding", respectively (Yanagimachi, 1994; Florman and Ducibella, 2006). Since PH-20 is enzymatically active at acid and neutral $\mathrm{pH}$, the neutral enzyme activity is postulated to function in hyaluronan degradation of the cumulus cell layer during sperm penetration. It is also proposed that the acid-active enzyme may be important for digestion of hyaluronan near or on the ZP surface for sperm binding to and penetration into the ZP (Drobnis et al., 1988; Cherr et al., 1996). However, recent works regarding mouse hyaluronidase (Baba et al., 2002; Kim et al., 2005) have weakened the above two possibilities. Hyaluronan zymography reveals that Hyal5 is enzymatically active in the $\mathrm{pH}$ range 5-7, and inactive at $\mathrm{pH} 3$ and 4 (Kim et al., 2005). The hyaluronidase activity of $\mathrm{Ph}-20$ is also detectable only at $\mathrm{pH} 6$ and 7 . Thus, the $\mathrm{pH}$ dependencies of these two mouse hyaluronidases are similar to each other, but distinguished from that of monkey soluble $\mathrm{PH}-20$. Moreover, no significant difference of the ability to bind cumulus-free, ZP-intact eggs is observed between wild-type and Ph-20-deficient acrosomeintact sperm (Baba et al., 2002). Indeed, ZP-binding assay in vitro demonstrates that both $\mathrm{Ph}-20$ and Hyal5 barely exhibit the binding activity, while Adam3 (Shamsadin et al., 1999; Nishimura et al., 2001 and 2004) is capable of binding to the ZP tightly (Kim et al., 2005). Neither Ph-20 nor Hyal5 may function in "secondary sperm-ZP binding."

Male mice lacking $\mathrm{Ph}-20$ are still fertile (Baba et al., 2002),
Fig. 2. Mouse sperm contain at least two isoforms of hyaluronidase. (A) Schematic representation of mouse Hyal5 and Ph-20. These two proteins contain three putative domains: the N-terminal signal peptide domain, catalytic domain as hyaluronidase, and $\mathrm{C}$-terminal recognition domain for attachment to GPI. Although the presence of ZP-binding domain (ZPB) has been postulated, both Hyal5 and Ph-20 barely exhibit the binding activity. Two disulfide-bond arrangements are assigned by the sequence similarities of Ph-20 and Hyal5 with guinea pig $\mathrm{PH}-20$. The sequence identities of the catalytic and possible ZP-binding domains between Hyal5 and Ph-20 are also indicated (percentages in parentheses). An arrow represents the position of the endoproteolytic cleavage site determined in Ph-20. (B) Insertion of Hyal5 onto mouse and rat chromosomes. Locations of Hyal4 (HYAL4), Ph-20 (PH-20), Hyal5, and RIKEN CDNA 6332401019 on mouse, rat, and human chromosomes are indicated. The genomic region carrying Hyal5 (approximately 60 to $90 \mathrm{kbp}$ ) is inserted only onto the mouse and rat chromosomes. TM, telomere; CM, centromere.
A

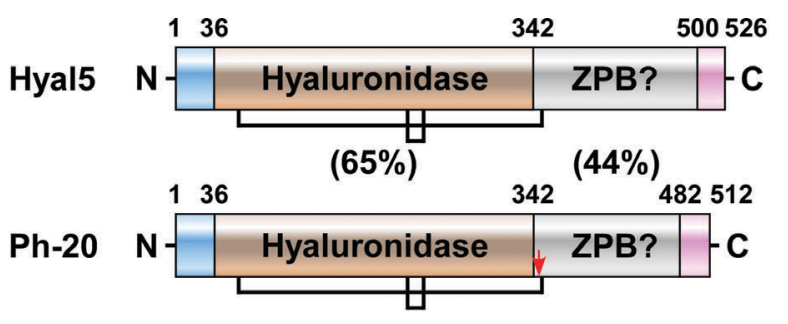

B

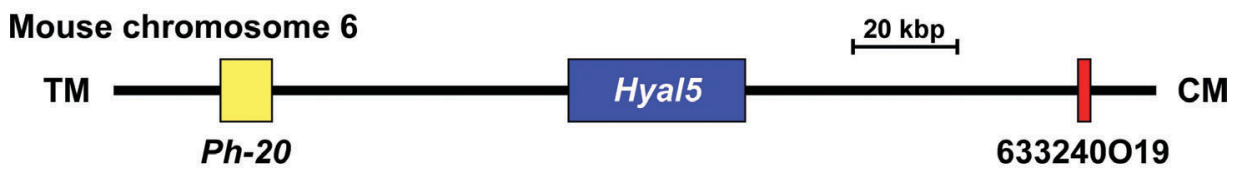

Rat chromosome 4

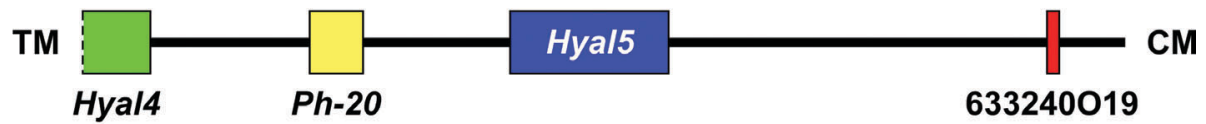

Human chromosome 7

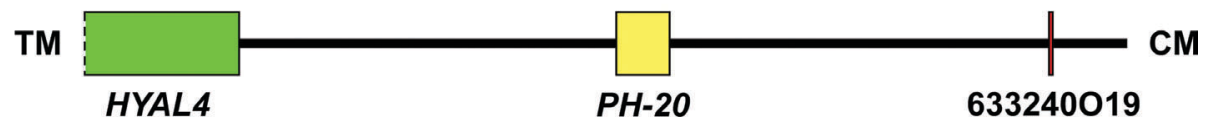


providing evidence that $\mathrm{Ph}-20$ is not essential for fertilization in the mouse. Although wild-type and Ph-20-deficient mouse sperm are capable of fertilizing the cumulus-intact eggs equally $3 \mathrm{~h}$ after insemination in vitro, the fertilization rate in $\mathrm{Ph}$-20-deficient sperm is significantly lower than that in wild-type sperm only at the early stages ( 1 and $2 \mathrm{~h}$ ) after insemination. When the eggs are inseminated with an equally mixed suspension of wild-type and Ph-20deficient sperm, the mutant sperm are approximately three times slower to fertilize the eggs than wild-type sperm. Moreover, no significant difference in sperm binding to the ZP is found between the wild-type and $\mathrm{Ph}-20$-deficient mice, as described above. Thus, the reduced fertilization rate in $\mathrm{Ph}-20$-deficient sperm is probably due to the delay of sperm penetration through the cumulus mass. It is further suggested that Hyal5 may play the crucial role in sperm penetration through the cumulus mass, possibly in cooperation with $\mathrm{Ph}-20$, because a Hyal5-enriched protein fraction prepared from $\mathrm{Ph}-20$-deficient mouse sperm is capable of dispersing cumulus cells from the cumulus mass (Kim et al., 2005).

\section{Sperm penetration through the egg zona pellucida}

Following passage through the cumulus cell layer, sperm gain access to the egg ZP, adhere and bind onto the ZP surface, undergo acrosome exocytosis induced by ZP3 known as one of three ZP glycoproteins in mouse and human, and then penetrate the ZP (Yanagimachi, 1994; Florman and Ducibella, 2006). Thus, the egg coat is the physical barrier for fertilizing sperm before the fusion event between sperm and egg takes place (the structural features of egg ZP and the mechanism of sperm-ZP interactions should be referred to excellent reviews described by $P$. Wassarman and B. Shur in this issue). Although the true mechanism is still unclear, it has long been hypothesized that sperm penetration through the ZP is dependent entirely on the mechanical force provided by sperm flagellar motility, or partly or mainly dependent on proteolytic hydrolysis of ZP assisted by acrosomal and/or

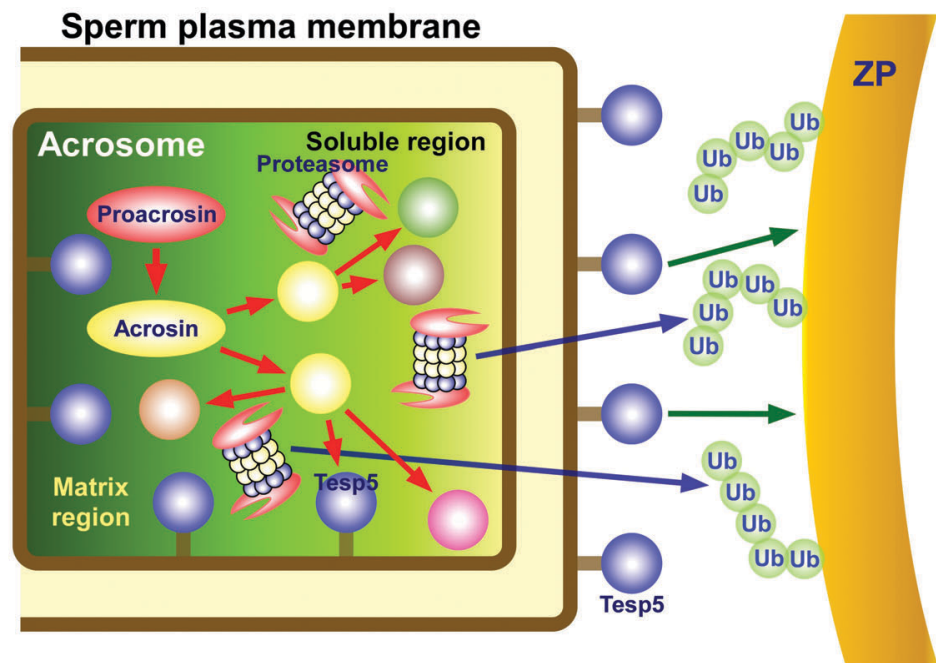

Fig. 3. Schematic representation of three candidate enzymes involved in sperm penetration through the egg zona pellucida in the mouse: acrosomal serine protease acrosin, serine protease Tesp5 GPl-anchored on the sperm membranes, and multi-subunit proteolytic holoenzyme proteasome in the acrosome. For details see the text. Ub, ubiquitin; ZP, zona pellucida.

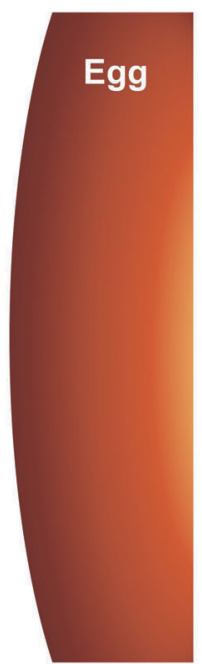

membrane proteases of sperm (Yanagimachi, 1994; Florman and Ducibella, 2006). There are three candidate enzymes involved in sperm penetration through the ZP: acrosomal serine protease acrosin (Baba et al., 1989), serine protease TESP5 GPI-anchored on the sperm membranes (Honda etal., 2002b), and multisubunit proteolytic holoenzyme proteasome in the acrosome (Sawada et al., 2002; Sutovsky et al., 2004) (Fig. 3). The physiological role of sperm entry into and penetration through the ZP is most likely to remove the acrosome from the fertilizing sperm. The reason is because only acrosome-reacted sperm are capable of fusing with the egg plasma membrane (Yanagimachi, 1994). Also, we must keep in mind that all sperm bound onto the egg ZP does not acrosome-react, and all acrosome-reacting or acrosomereacted sperm on the ZP surface does not penetrate the ZP.

Acrosin has long been believed to participate in limited proteolysis of the egg ZP to assist sperm in penetrating the egg coat. However, acrosin-deficient mice conclusively show that this serine protease is not essential both for sperm penetration through the ZP and for fertilization (Baba et al., 1994). The loss of acrosin results in delayed sperm penetration of the ZP at the early stages of fertilization in vitro, probably owing to the delay in dispersal of acrosomal proteins during the acrosome reaction (Yamagata et al., 1998b). Indeed, when cumulus-intact eggs are inseminated with an equally mixed suspension of wild-type and acrosindeficient mouse sperm, only wild-type sperm fertilize the eggs, verifying a reduced ability of the mutant sperm to penetrate the ZP or fertilize the eggs (Adham et al., 1997). Moreover, $p$ aminobenzamidine, a competitive inhibitor for trypsin-like serine proteases, blocks penetration of acrosin-deficient sperm through the ZP (Yamagata etal., 1998a). Thus, other $p$-aminobenzamidinesensitive protease(s) besides acrosin may function in the penetration event, possibly in cooperation with acrosin. This speculation appears reasonable because acrosin is present not on the sperm surface but in the acrosome.

In an attempt to characterize a gelatin-hydrolyzing serine protease with a molecular mass of $42 \mathrm{kDa}$ present in the sperm extracts of wild-type and acrosin-deficient mice (Baba et al., 1994; Yamagata et al., 1998a and 1999), five different serine proteases, termed Tesp1 (testicular serine protease 1), Tesp2, Tesp3, Tesp4, and Tesp5, were identified as candidates for the $42-\mathrm{kDa}$ serine protease (Kohno et al., 1998; Ohmura et al., 1999; Honda et al., 2002b). Of these five serine proteases, only Tesp5, which is identical to esp-1 (Inoue et al., 1998), testisin (Scarman et al., 2001), and tryptase 4 (Wong et al., 2001) belonging to a 21st member of serine protease family Prss21, corresponds to the 42-kDa sperm protein (Honda et al., $2002 b)$. Tesp5 is initially synthesized as a 43$\mathrm{kDa}$ precursor in the testis, and the precursor is converted into the $42-$ and $41-\mathrm{kDa}$ active enzymes during sperm transport in the epididymis. The enzymatic property of Tesp5 is similar to but distinguishable from those of acrosin and trypsin by the substrate specificity and inhibitory effects of serine protease inhibitors. Importantly, Tesp5 is localized on 
the sperm plasma membrane and as a GPI-anchored protein (Honda et al., 2002b; Kim et al., 2005).

To elucidate the functional role of Tesp5 in fertilization, we have produced mutant mice lacking Tesp5 (unpublished data). Our preliminary data indicate that Tesp5-deficient epididymal sperm are severely defective in the ability to undergo the ZPinduced acrosome reaction, to penetrate the $\mathrm{ZP}$, and to fuse with the egg membrane in vitro. Thus, Tesp5 may play an important role in the acrosome reaction and subsequent sperm penetration through the ZP at least in the mouse. Combining the experimental results concerning the phenotypes of acrosin- and Tesp5-deficient mouse sperm, the normal presence of Tesp5 on acrosindeficient sperm (unpublished data) may explain the ability of acrosin-deficient sperm to penetrate the ZP despite the time delay (Baba et al., 1994). Intriguingly, Tesp5 is activated by addition of exogenous pancreatic trypsin to protein extracts of acrosindeficient sperm in vitro (Yamagata et al., 1998a and 1998b; Honda et al., 2002a), thus implying that Tesp5 may be activated by acrosin released from the acrosome onto the ZP surface after acrosome exocytosis. We have currently produced mutant mice lacking both acrosin and Tesp5. Comparative analysis of acrosin, Tesp5-, and both-deficient mouse sperm presumably provides a new insight into the mechanism of sperm penetration through the ZP.

In this review, we discuss the possible mechanism of sperm penetration through the egg ZP mainly in the mouse model, but there is a discrepancy in the serine protease systems between mouse and other animal sperm (Honda et al., 2002a). On the basis of gelatin zymography, the level of total gelatin-hydrolyzing activity in mouse sperm is much lower than those in rat and hamster sperm (Yamagata et al., 1999). Notably, rat and hamster sperm barely contain Tesp5, whereas a very small amount of acrosin is present in mouse sperm as compared with rat and hamster sperm. These data imply that the serine protease system in the mouse may differ from those in other animals, including the rat and hamster, and hence the mechanism of sperm penetration through the ZP may be essentially similar but different between the mouse and other mammals.

Two trypsin-like serine proteases, acrosin and spermosin, and ubiquitin-proteasome system in sea squirts and sea urchins are demonstrated to play key roles in sperm binding to and penetration through the egg vitelline envelope (Sawada et al., 1984 and 2002; Sawada and Someno, 1996; Yokota and Sawada, 2007). Ascidian sperm contain 265 or 205 proteasome, ubiquitin, and ubiquitin-conjugating enzyme that are released from the acrosome to ubiquitinate and degrade a sperm receptor, HrVC70, as an analogue of mammalian ZP3 on the surface of the vitelline coat during fertilization (Sawada etal., 2002). Acrosomal proteasomes of sea urchin sperm are responsible for the acrosome reaction and sperm penetration through the vitelline envelope (Yokota and Sawada, 2007). In mammals, proteasome subunits are also localized in the acrosome of human (Morales et al., 2004; Pasten et al., 2005), pig (Sutovsky et al., 2004), and mouse sperm (unpublished data). Pig sperm proteasomes present both in the acrosomal matrix and on the inner acrosomal membrane are released by the acrosome reaction to degrade already ubiquitinated ZP proteins on the ZP surface (Sutovsky et al., 2004). The proteosome inhibitors and antibodies against proteasome subunits are capable of blocking completely sperm penetration through the egg ZP in the mouse and pig, without affecting sperm capacitation, sperm motility, sperm-ZP binding, and acrosome reaction (Wang et al., 2002; Sutovsky et al., 2004). Thus, the ubiquitin-proteasome system is a reliable tool for penetration of a fertilizing sperm through the ZP. However, the functional correlations in limited hydrolysis of the ZP among acrosin, Tesp5, and proteasomes of mammalian sperm (acrosin, spermosin, and proteasomes for the ascidian model) still remain to be uncovered. At any rate, the physiological importance of acrosome exocytosis should be revisited to elucidate the mechanism of sperm passage through the ZP, because acrosin and $26 \mathrm{~S}$ or $20 \mathrm{~S}$ proteasome are localized in the sperm acrosome.

\section{Acknowledgement}

This study was partly supported by Grant-in-Aids for Scientific Researches from Ministry of Education, Culture, Sports, Science and Technology in Japan (MEXT) and Japan Society for the Promotion of Science (JSPS).

\section{References}

ADHAM, I. M., NAYERNIA, K., AND ENGEL, W. (1997). Spermatozoa lacking acrosin protein show delayed fertilization. Mol. Reprod. Dev. 46: 370-376.

AUSTIN, C. R. (1960). Capacitation and the release of hyaluronidase from spermatozoa. J. Reprod. Fertil. 3: 310-311.

BABA, D., KASHIWABARA, S., HONDA, A., YAMAGATA, K., WU, Q., IKAWA, M., OKABE, M., AND BABA, T. (2002). Mouse sperm lacking cell surface hyaluronidase $\mathrm{PH}-20$ can pass through the layer of cumulus cells and fertilize the egg. J. Biol. Chem. 277: 30310-30314.

BABA, T., AZUMA, S., KASHIWABARA, S., AND TOYODA, Y. (1994). Sperm from mice carrying a targeted mutation of the acrosin gene can penetrate the oocyte zona pellucida and effect fertilization. J. Biol. Chem. 269: 31845-31849.

BABA, T., KASHIWABARA, S., WATANABE, K., ITOH, H., MICHIKAWA, Y., KIMURA, K., TAKADA, M., FUKAMIZU, A., AND ARAI, Y. (1989). Activation and maturation mechanisms of boar acrosin zymogen based on the deduced primary structure. J. Biol. Chem. 264: 11920-11927.

CHERR, G. N., MEYERS, S. A., YUDIN, A. I., VANDEVOORT, C. A., MYLES, D. G., PRIMAKOFF, P. AND OVERSTREET, J. W. (1996). The PH-20 protein in cynomolgus macaque spermatozoa: identification of two different forms exhibiting hyaluronidase activity. Dev. Biol. 175: 142-153.

CHERR, G. N., YUDIN, A. I., AND OVERSTREET, J. W. (2001). The dual functions of GPI-anchored PH-20: hyaluronidase and intracellular signaling. Matrix Biol. 20: 515-525.

CSÓKA, A. B., FROST, G. I., AND STERN, R. (2001). The six hyaluronidase-like genes in the human and mouse genomes. Matrix Biol. 20: 499-508.

CSÓKA, A. B., SCHERER, S. W., AND STERN, R. (1999). Expression analysis of paralogous human hyaluronidase genes clustered on chromosomes 3p21 and 7q31. Genomics 60: 356-361.

DROBNIS, E. Z., YUDIN, A. I., CHERR, G. N., AND KATZ, D. F. (1988). Hamster sperm penetration of the zona pellucida: kinematic analysis and mechanical implications. Dev. Biol. 130: 311-323.

FLORMAN, H. M. AND DUCIBELLA, T. (2006). Fertilization in mammals. In The Knobil and Neill's Physiology of Reproduction. Neill, J. D. ed. (New York: Elsevier), pp. 55-112.

FRAZER, L. R. (1982). p-Aminobenzamidine, an acrosin inhibitor, inhibits mouse sperm penetration of the zona pellucida but not the acrosome reaction. $J$. Reprod. Fertil. 65: 185-194.

FROST, G. I., CSÓKA, T., AND STERN, R. (1996). The hyaluronidases: a chemical, biological, and clinical overview. Trends Glycosci. Glycotech. 8: 419-434.

GMACHL, M. AND KREIL, G. (1993). Bee venom hyaluronidase is homologous to a membrane protein of mammalian sperm. Proc. Natl. Acad. Sci. USA90: 35693573.

GMACHL, M., SAGAN, S., KETTER, S., AND KREIL, G. (1993). The human sperm protein $\mathrm{PH}-20$ has hyaluronidase activity. FEBS Lett. 336: 545-548. 
HONDA, A., SIRUNTAWINETI, J., AND BABA, T. (2002a). Role of acrosomal matrix proteases in sperm-zonapellucida interactions. Hum. Reprod. Update 8: 405-412.

HONDA, A., YAMAGATA, K., SUGIURA, S., WATANABE, K., AND BABA, T. (2002b). A mouse serine protease TESP5 is selectively included into lipid rafts of sperm membrane presumably as a glycosylphosphatidylinositol-anchored protein. J. Biol. Chem. 277: 16976-16984.

HUNNICUT, G. R., MAHAN, K., LATHROP, W. F., RAMARAO, C. S., MYLES, D. G., AND PRIMAKOFF, P. (1996a). Structural relationship of sperm soluble hyaluronidase to the sperm membrane protein $\mathrm{PH}-20$. Biol. Reprod. 54: 13431349.

HUNNICUTT, G. R., PRIMAKOFF, P., AND MYLES, D. G. (1996b). Sperm surface protein $\mathrm{PH}-20$ is bifunctional: one activity is a hyaluronidase and a second, distinct activity is required in secondary sperm-zona binding. Biol. Reprod. 55: 80-86.

INOUE, M., KANBE, N., KUROSAWA, M., AND KIDO, H. (1998). Cloning and tissue distribution of a novel serine protease esp-1 from human eosinophils. Biochem. Biophys. Res. Commun. 252: 307-312.

KIM, E., BABA, D., KIMURA, M., YAMASHITA, M., KASHIWABARA, S., AND BABA, T. (2005). Identification of a hyaluronidase, Hyal5, involved in penetration of mouse sperm through cumulus mass. Proc. Natl. Acad. Sci. USA 102: 18028-18033.

KOHNO, N., YAMAGATA, K., YAMADA, S., KASHIWABARA, S., SAKAI, Y., AND BABA, T. (1998). Two novel testicular serine proteases, TESP1 and TESP2, are present in the mouse sperm acrosome. Biochem. Biophys. Res. Commun. 245: 658-665.

KREIL, G. (1995). Hyaluronidases: a group of neglected enzymes. Protein Sci. 4: 1666-1669.

MARKOVI-HOUSLEY, Z., MIGLIERINI, G., SOLDATOVA, L., RIZKALLAH, P. J., MÜLLER, U., AND SCHIRMER, T. (2000). Crystal structure of hyaluronidase, a major allergen of bee venom. Structure 8: 1025-1035.

MILLER, K. A., SHAO, M., AND MARTIN-DELEON, P. A. (2007). Hyalp1 in murine sperm function: evidence for unique and overlapping functions with other reproductive hyaluronidases. J. Androl. 28: 67-76.

MIYAMOTO, H. AND CHANG, M.C. (1973). Effecs of protease inhibitors on the fertilizing capacity of hamster spermatozoa. Biol. Reprod. 9: 533-537.

MORALES, P., PIZARRO, E., KONG, M., AND JARA, M. (2004). Extracellular localization of proteasomes in human sperm. Mol. Reprod. Dev. 68: 115-124.

MYLES, D. G. AND PRIMAKOFF, P. (1997). Why did the sperm cross the cumulus? To get to the oocyte. Functions of the sperm surface proteins $\mathrm{PH}-20$ and fertilin in arriving at, and fusing with, the egg. Biol. Reprod. 56: 320-327.

NISHIMURA, H., CHO, C., BRANCIFORTE, G. R., MYLES, D. G., AND PRIMAKOFF, P. (2001). Analysis of loss of adhesive function in sperm lacking cyritestin of fertilin B. Dev. Biol. 233: 204-213.

NISHIMURA, H., KIM, E., NAKANISHI, T., AND BABA, T. (2004). Possible function of the ADAM1a/ADAM2 fertilin complex in the appearance of ADAM3 on the sperm surface. J. Biol. Chem. 279: 34957-34962.

OHMURA, K., KOHNO, N., KOBAYASHI, Y., YAMAGATA, K., SATO, S., KASHIWABARA, S., AND BABA, T. (1999). A homologue of pancreatic trypsin is localized in the acrosome of mammalian sperm and is released during acrosome reaction. J. Biol. Chem. 274: 29426-29432.

OVERSTREET, J. W., LIN, Y., YUDIN, A. I., MEYERS, S. A., PRIMAKOFF, P., MYLES, D. G., KATZ, D. F., AND VANDEVOORT, C. A. (1995). Location of the $\mathrm{PH}-20$ protein on acrosome-intact and acrosome-reacted spermatozoa of cynomolgus macaques. Biol. Reprod. 52: 105-114.

PASTEN, C., MORALES, P., AND KONG, M. (2005). Role of the sperm proteasome during fertilization and gamete interaction in the mouse. Mol. Reprod. Dev. 71 : 209-219.

PHELPS, B. M., KOPPEL, D. E., PRIMAKOFF, P., AND MYLES, D. G. (1990). Evidence that proteolysis of the surface is an initial step in the mechanism of formation of sperm cell surface domains. J. Cell Biol. 111: 1839-1847.

PHELPS, B. M., PRIMAKOFF, P., KOPPEL, D. E., LOW, M. G., AND MYLES, D. G. (1988). Restricted lateral diffusion of PH-20, a PI-anchored sperm membrane protein. Science 240: 1780-1782.

PRIMAKOFF, P., HYATT, H. AND MYLES, D. G. (1985). A role for the migrating sperm surface antigen $\mathrm{PH}-20$ in guinea pig sperm binding to the egg zona pellucida. J. Cell Biol. 101: 2239-2244.

REITINGER, S., LASCHOBER, G. T., FEHRER, C., GREIDERER, B., AND LEPPERDINGER, G. (2007). Mouse testicular hyaluronidase-like proteins SPAM1 and HYAL5 but not HYALP1 degrade hyaluronan. Biochem. J. 401: 7985.

SAWADA, H., SAKAI, N., ABE, Y., TANAKA, E., TAKAHASHI, Y., FUJINO, J., KODAMA, E., TAKIZAWA, S. AND YOKOSAWA, H. (2002). Extracellular ubiquitination and proteasome-mediated degradation of the ascidian sperm receptor. Proc. Natl. Acad. Sci. USA 99: 1223-1228.

SAWADA, H. AND SOMENO, T. (1996). Substrate specificity of ascidian sperm trypsin-like proteases, spermosin and acrosin. Mol. Reprod. Dev. 45: 240-243.

SAWADA, H., YOKOSAWA, H., AND ISHII, S. (1984). Purification and characterization of two types of trypsin-like enzymes from sperm of the ascidian (Prochordata) Halocynthia roretzi. Evidence for the presence of spermosin, a novel acrosin-like enzyme. J. Biol. Chem. 259: 2900-2904.

SCARMAN, A. L., HOOPER, J. D., BOUCAUT, K. J., SIT, M. L., WEBB, G. C., NORMYLE, J. F., AND ANTAILS, T. M. (2001). Organization and chromosomal localization of the murine Testisin gene encoding a serine protease temporally expressed during spermatogenesis. Eur. J. Biochem. 268: 1250-1258.

SHAMSADIN, R., ADHAM, I. M., NAYERNIA, K., HEINLEIN, U. A., OBERWINKLER, H., AND ENQEL, W. (1999). Male mice deficient for germ-cell cyritestin are infertile. Biol Reprod. 287: 1445-1451.

SNELL, W. J. AND WHITE, J. M. (1996). The molecules of mammalian fertilization. Cel/85: 629-637.

STAMBAUGH, R., BRACKETT, B. G., AND MASTROIANNI, L. (1969). Inhibition of in vitro fertilization of rabbit ova by trypsin inhibitors. Biol. Reprod. 1: 223-227.

SUTOVSKY, P., MANANDHAR, G., MCCAULEY, T. C., CAAMAÑO, J. N., SUTOVSKY, M., THOMPSON, W. E., AND DAY, B. N. (2004). Proteasomal interference prevents zona pellucida penetration and fertilization in mammals. Biol. Reprod. 71: 1625-1637.

THALER, C. D. AND CARDULLO, R. A. (1995). Biochemical characterization of a glycosylphosphatidylinositol-linked hyaluronidase on mouse sperm. Biochemistry 34: 7788-7795.

WANG, H. M., SONG, C. C., DUAN, C. W., SHI, W. X., LI, C. X., CHEN, D. Y., AND WANG, Y. C. (2002). Effects of ubiquitin-proteasome pathway on mouse sperm capacitation, acrosome reaction and in vitro fertilization. Chin. Sci. Bull. 47: 127132.

WASSARMAN, P. M. (1999). Mammalian Fertilization: molecular aspects of gamete adhesion, exocytosis, and fusion. Cel/96: 175-183.

WONG, G. W., LI, L., MADHUSUDHAN, M.S., KRILIS, S. A., GURISH, M. F., ROTHENBERG, M. E., SALI, A., AND STEVENS, R. L (2001). Tryptase4, a new member of the chromosome 17 family of mouse serine proteases. J. Biol. Chem. 276: 20648-20658.

YAMAGATA, K., HONDA, A., KASHIWABARA, S., AND BABA, T. (1999). Difference of acrosomal serine protease system between mouse and other rodent sperm. Dev. Genet. 25: 115-122.

YAMAGATA, K., MURAYAMA, K., KOHNO, N., KASHIWABARA, S., AND BABA, T. (1998a). p-Aminobenzamidine-sensitive acrosomal protease(s) other than acrosin serve the sperm penetration of the egg zona pellucida in mouse. Zygote 6: 311-319.

YAMAGATA, K., MURAYAMA, K., OKABE, M., TOSHIMORI, K., NAKANISHI, T., KASHIWABARA, S., AND BABA, T. (1998b). Acrosin accelerates the dispersal of sperm acrosomal proteins during acrosome reaction. J. Biol. Chem. 273: 10470-10474.

YANAGIMACHI, R. (1994). Mammalian fertilization. In The Physiology of Reproduction. Knobil E. and Neill J. eds. (New York: Raven Press), pp. 189-317.

YOKOTA, N. AND SAWADA, H. (2007) Sperm proteasomes are responsible for the acrosome reaction and sperm penetration of the vitelline envelope during fertilization of the sea urchin Pseudocentrotus depressus. Dev. Biol. 308: 222-231.

ZHANG, H. AND MARTIN-DELEON, P. A. (2001). Mouse epididymal Spam1 (PH20 ) is released in vivo and in vitro, and Spam 1 is differentially regulated in testis and epididymis. Biol. Reprod. 65: 1586-1593.

ZHANG, H., SHERTOK, S., MILLER, K. A., TAYLOR, L., AND MARTIN-DELEON, P. A. (2005). Sperm dysfunction in the $\mathrm{Rb}(6.16)$ - and $\mathrm{Rb}(6.15)$-bearing mice revisited: involvement of Hyalp1 and Hyal5. Mol. Reprod. Dev. 72: 404-410. 


\section{Related, previously published Int. J. Dev. Biol. articles}

See our recent Special Issue Developmental Biology in Poland edited by Tarkowski, Maleszewski and Kloc at: http://www.ijdb.ehu.es/web/contents.php?vol=52\&issue=2-3

See our recent Special Issue Ear Development edited by Fernando Giraldez and Bernd Fritzsch at: http://www.ijdb.ehu.es/web/contents.php?vol=51\&issue=6-7

Gene mapping of sperm quality parameters in recombinant inbred strains of mice Aniela Golas, Anna Dzieza, Katarzyna Kuzniarz and Jozefa Styrna Int. J. Dev. Biol. (2008) 52: 287-293

Genetic control of gamete quality in the mouse - a tribute to Halina Krzanowska Jozefa Styrna

Int. J. Dev. Biol. (2008) 52: 195-199

Molecular aspects of avian oogenesis and fertilisation Bozenna Olszanska and Urszula Stepinska Int. J. Dev. Biol. (2008) 52: 187-194

DNA methylation state is preserved in the sperm-derived pronucleus of the pig zygote Young-Sun Jeong, Seungeun Yeo, Jung-Sun Park, Deog-Bon Koo, Won-Kyung Chang, Kyung-Kwang Lee and Yong-Kook Kang Int. J. Dev. Biol. (2007) 51: 707-714

Distinct mechanisms underlie sperm-induced and protease-induced oolemma block to sperm penetration. Sebastian Komorowski, Katarzyna Szczepanska and Marek Maleszewski Int. J. Dev. Biol. (2003) 47: 65-69

Mammalian oocyte activation: lessons from the sperm and implications for nuclear transfer.

R Alberio, V Zakhartchenko, J Motlik and E Wolf Int. J. Dev. Biol. (2001) 45: 797-809

Association of egg zona pellucida glycoprotein mZP3 with sperm protein sp56 during fertilization in mice.

$\mathrm{N}$ Cohen and $\mathrm{P} M$ Wassarman

Int. J. Dev. Biol. (2001) 45: 569-576

Sperm-egg interaction at fertilization: glycans as recognition signals.

F Rosati, A Capone, C D Giovampaola, C Brettoni and R Focarelli

Int. J. Dev. Biol. (2000) 44: 609-618

Requirement of protamine for maintaining nuclear condensation of medaka (Oryzias latipes) spermatozoa shed into water but not for promoting nuclear condensation during spermatogenesis.

Y Shimizu, K Mita, M Tamura, K Onitake and M Yamashita Int. J. Dev. Biol. (2000) 44: 195-199

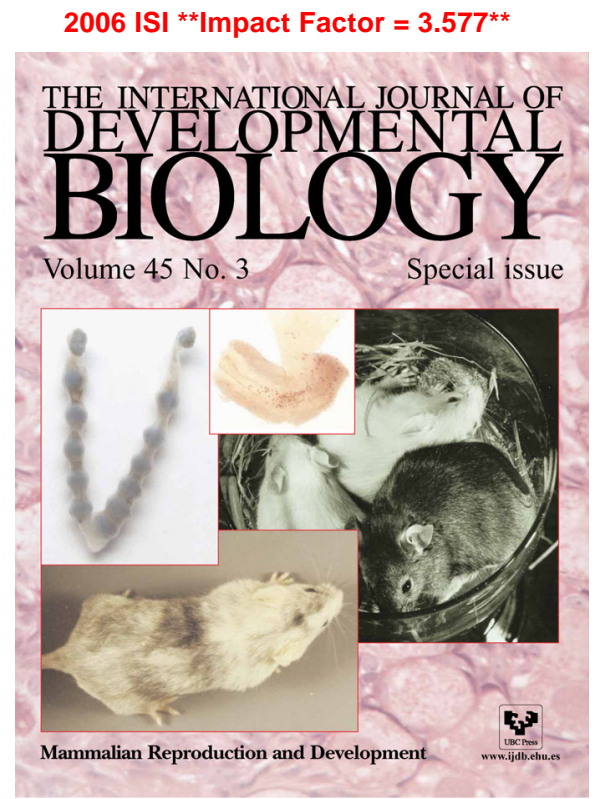

